\title{
Revisit the Candidacy of Brain Cell Types as the Cell(s) of Origin for Human High-Grade Glioma
}

\author{
Fangjie Shao and Chong Liu* \\ Department of Pathology and Pathophysiology, Zhejiang University School of Medicine, Hangzhou, China
}

\section{OPEN ACCESS}

Edited by:

Margaret Su-chun Ho,

ShanghaiTech University, China

Reviewed by:

Mirko H. H. Schmidt,

Universitätsmedizin der Johannes

Gutenberg-Universität Mainz,

Germany

Francois M. Vallette,

Institut National de la Santé et de la

Recherche Médicale (INSERM),

France

*Correspondence:

Chong Liu

chongliu77@zju.edu.cn

Received: 27 November 2017 Accepted: 05 February 2018

Published: 21 February 2018

Citation:

Shao F and Liu C (2018) Revisit the Candidacy of Brain Cell Types as the Cell(s) of Origin for Human High-Grade Glioma.

Front. Mol. Neurosci. 11:48. doi: 10.3389/fnmol.2018.00048
High-grade glioma, particularly, glioblastoma, is the most aggressive cancer of the central nervous system (CNS) in adults. Due to its heterogeneous nature, glioblastoma almost inevitably relapses after surgical resection and radio-/chemotherapy, and is thus highly lethal and associated with a dismal prognosis. Identifying the cell of origin has been considered an important aspect in understanding tumor heterogeneity, thereby holding great promise in designing novel therapeutic strategies for glioblastoma. Taking advantage of genetic lineage-tracing techniques, performed mainly on genetically engineered mouse models (GEMMs), multiple cell types in the CNS have been suggested as potential cells of origin for glioblastoma, among which adult neural stem cells (NSCs) and oligodendrocyte precursor cells (OPCs) are the major candidates. However, it remains highly debated whether these cell types are equally capable of transforming in patients, given that in the human brain, some cell types divide so slowly, therefore may never have a chance to transform. With the recent advances in studying adult NSCs and OPCs, particularly from the perspective of comparative biology, we now realize that notable differences exist among mammalian species. These differences have critical impacts on shaping our understanding of the cell of origin of glioma in humans. In this perspective, we update the current progress in this field and clarify some misconceptions with inputs from important findings about the biology of adult NSCs and OPCs. We propose to re-evaluate the cellular origin candidacy of these cells, with an emphasis on comparative studies between animal models and humans. Keywords: cell of origin, high-grade glioma, glioblastoma, adult neural stem cells (NSCs), oligodendrocyte
precursor cells (OPC), genetically engineered mouse models (GEMMs), lineage tracing

\section{INTRODUCTION}

Adult gliomas are the most common cancers of the central nervous system (CNS) (Louis, 2006; Perry and Wesseling, 2016). Despite many years of efforts in both basic research and clinical practice, the prognosis of malignant gliomas, particularly the most advanced one, glioblastoma multiforme (GBM), remains dismal. This lack of progress is largely associated with high interand intra-tumoral heterogeneity. Tumor tissues from not only different patients, but also from the same ones, can be stratified into distinct morphopathological groups or molecular subtypes (Verhaak et al., 2010; Snuderl et al., 2011; Brennan et al., 2013; Kim J. et al., 2015; Wang et al., 2016, 2017). Such heterogeneity is generally considered as the main reason for drug resistance and high recurrence rate during treatment. 
A cell of origin is the normal progenitor from which all the neoplastic cells of a given type of cancer develop (Visvader, 2011; Chaffer and Weinberg, 2015). Identification of the cell of origin can give critical insights into the principles dictating tumor heterogeneity, therefore holding great promise in understanding the cancer etiology, and facilitating the design of effective therapeutic strategies. In this Perspective, we review the current progress in the research of the cell of origin of glioma. Together with new findings in NSCs and OPCs from both rodents and large-brained mammals including humans, we propose to carefully re-evaluate the candidacy of several popular cell types that have been believed as the potential cells of origin of glioma in humans.

\section{CNS CELL TYPES RELEVANT TO GLIOMA ETIOLOGY: THEIR LINEAGE RELATIONSHIP AND SOME IMPORTANT UPDATES}

Knowing the properties of neural cell types and their lineage relationship will help understanding their potential contributions to the etiology of human glioma. Neural cells in the adult CNS are grossly classified as neurons, astrocytes, oligodendrocyte precursor cells (OPCs), and oligodendrocytes. In addition to these lineage-committed progenitor and mature cells, specialized stem cells, termed adult neural stem cells (NSCs) exist within restricted regions such as the subventricular zone (SVZ) next to the lateral ventricle, and the subgranular zone (SGZ) of the hippocampus (Ming and Song, 2011), in the adult brain. Both SVZ adult NSCs and OPCs have been implicated as the major candidates for glioma cell of origin, therefore, deserving a little more discussion.

\section{Adult Neural Stem Cells (NSCs)}

Adult NSCs (also termed B1 cells), which were best studied in rodents, have been generally believed to be able to persistently self-renew, and give rise to multiple neuronal and glial cell types (Alvarez-Buylla et al., 2001). Recent progresses in NSC biology, however, may suggest a quite different scenario. By using a temporal Histone 2B-EGFP marking system or barcoded retroviral labeling-based clonal analysis, two groups independently reported that postnatal B1 cells are derived from embryonic NSCs that divide during mid-fetal development and then remain quiescent until they reactivate, thus generating progeny in the postnatal brain (Fuentealba et al., 2015; Furutachi et al., 2015). Surprisingly, clonal analysis unraveled that postnatally, a single $\mathrm{B} 1$ cell neither divides repeatedly to produce generations of olfactory bulb $(\mathrm{OB})$ neurons, nor gives rise to cortical glial cells and $\mathrm{OB}$ neurons simultaneously, raising an interesting possibility that adult NSCs may not systematically self-renew (Fuentealba et al., 2015) (see also Figure 1A). Therefore, although adult NSCs exhibit remarkable self-renewal potential and differentiation plasticity in culture (Doetsch et al., 1999; Codega et al., 2014), it remains highly debated whether, in the brain, they conform to the hardwired definition of tissue stem cells, as seen in the case of hematopoietic or intestinal stem cells (Batlle and Clevers, 2017).

\section{Oligodendrocyte Precursor Cells (OPCs)}

Oligodendrocyte precursor cells were initially thought to function solely as transient forms of glial progenitors, to generate mature oligodendrocytes. Nevertheless, recent studies show that even though some OPCs indeed differentiate, many of them retain the ability to self-renew (Nishiyama et al., 2009; Vigano and Dimou, 2016) (see also Figure 1A). By using a sensitive DNA-labeling approach to mark cells undergoing proliferation, Yeung et al. (2014) showed that all OPCs in the adult mouse brain were dividing. Strikingly, Garcia-Marques et al. (2014 observed that at the clonal level, a single OPC could give rise to up to 400 cells in the adult mouse brain, therefore unequivocally demonstrating that OPCs are a bona fide self-renewable cell population in vivo. Given that OPCs make up 5-10\% of all cells in the brain (Dawson et al., 2003), using the absolute number as the criteria, OPCs should be viewed as the largest proliferation pool in the mammalian brain. In addition to selfrenewal, OPCs have been reported to exhibit some lineage plasticity. Despite being a matter of intensive debate, OPCs were shown to be able to differentiate into astrocytes and/or neurons in vivo (Rivers et al., 2008; Zhu et al., 2008, 2011; Richardson et al., 2011), and can be reprogrammed into the NSC-like status in vitro (Kondo and Raff, 2000), thus resembling NSCs in ways stronger than those previously considered (Richardson et al., 2011).

\section{THE RESEARCH PROGRESS OF GLIOMA CELLULAR ORIGINS}

\section{NSCs as the Cell of Origin: Evidence and Concerns}

Adult NSCs have been widely viewed as the most possible cell of origin for high-grade glioma, given their prominent property to self-renew, and the remarkable plasticity to differentiate into multiple neural cell types (Doetsch et al., 1999; Alvarez-Buylla et al., 2001; Stiles and Rowitch, 2008). In addition, cancer stem cells (CSCs) isolated from human GBMs share many markers normally expressed by NSCs (such as Nestin, GFAP, CD133, and Sox2), and are able to form renewable NSC-like spheres in culture (Singh et al., 2004; Bao et al., 2006). Furthermore, mouse and human NSCs can be transformed in vitro; they gain the capacity to develop into gliomas after implantation into host mice (Bachoo et al., 2002; Duan et al., 2015). Importantly, delivery of DNA or viral vehicles into the embryonic, neonatal, or adult SVZ (the brain structure where NSCs reside) to introduce overexpression of oncogenes and/or knockout/knockdown of tumor suppressor genes could efficiently generate high-grade glioma in mice (Alcantara Llaguno et al., 2009; Marumoto et al., 2009; Breunig et al., 2015; Zuckermann et al., 2015). Intriguingly, human glioblastomas were frequently diagnosed next to the SVZ, further supporting the possibility that they originated from NSCs (Barami et al., 2009). More direct evidence was obtained from 


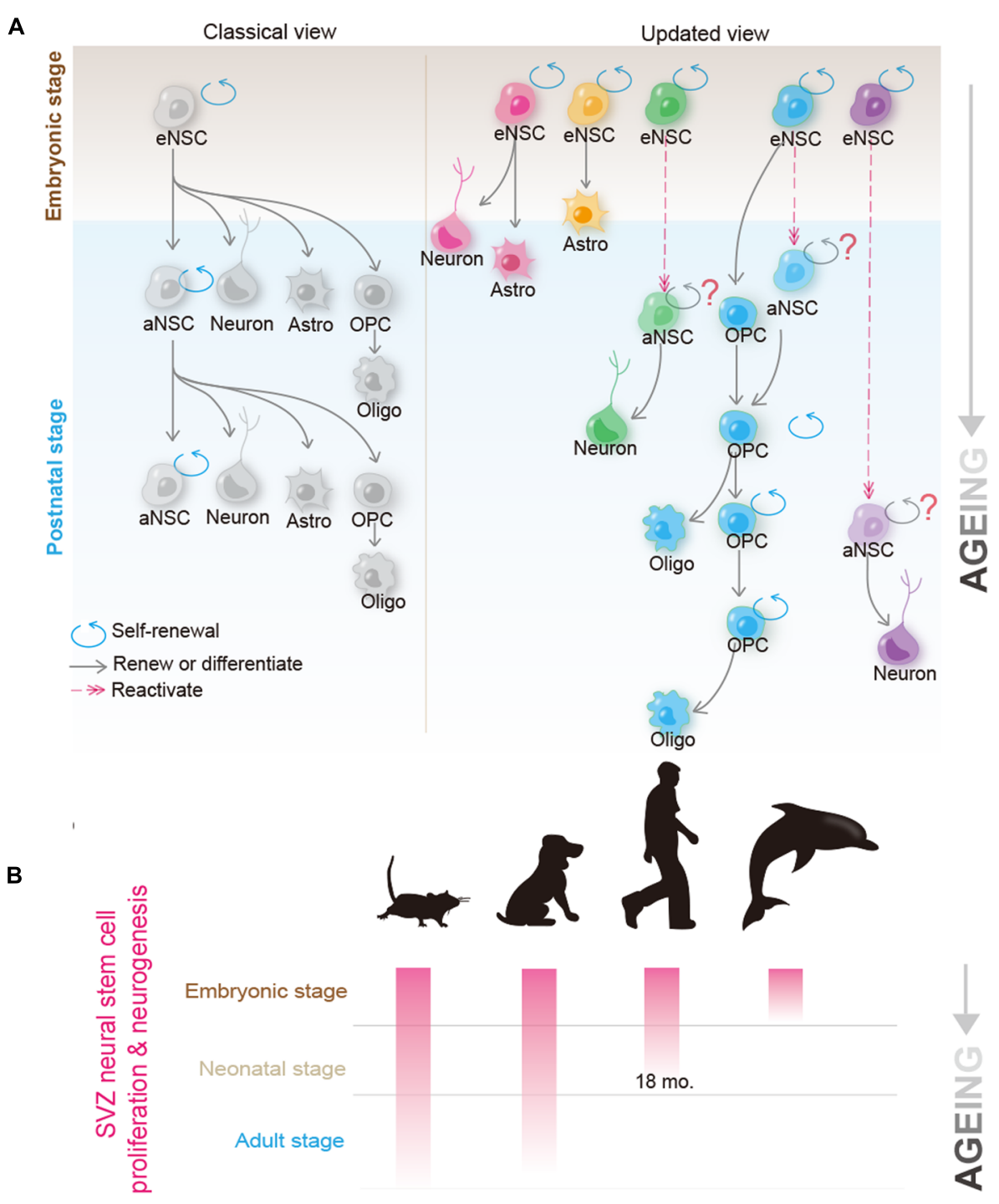

FIGURE 1 | Recent progress in the biology of neural stem cells (NSCs) and oligodendrocyte precursor cells (OPCs) provides new insights into their candidacy as the cell of origin for human glioblastoma. (A) Classical (left) and the updated (right) view of the NSC behavior in the brain. In the classical view, it was believed that a single NSC can repeatedly self-renew for many generations and give rise to new NSCs; at the same time, it possesses the potential to differentiate into neurons, astrocyte and OPCs. OPCs can further differentiate into mature oligodendrocytes. Recent studies using mouse models suggest that adult B1 cells (adult form of NSCs) are derived from eNSCs that actively proliferate at $\sim$ E14.5. These embryonic NSCs remain quiescent until they are reactivated at the adult stage. Though as a whole population, adult NSCs continuously proliferate and give rise to olfactory bulb (OB) neurons and glial cells, they are extremely heterogeneous at the single cell level. Clonal analysis revealed that a single adult NSC can either give rise to OB neurons or glial cells (such as astrocytes and oligodendrocytes), but rarely to both cell types. Furthermore, many, if not all, adult NSCs cannot bud off OB neurons and simultaneously self-renew, raising the question of whether adult NSCs conform to the hardwired definition of self-renewable tissue stem cells (Fuentealba et al., 2015; Furutachi et al., 2015). On the other hand, despite OPCs originally being derived from NSCs during early development, and adult NSCs contributing to the OPC pool to some extent, in the normal brain, most adult OPCs are generated from the locally resident OPCs. Clonal analysis further revealed that adult OPCs can self-renew continuously (Garcia-Marques et al., 2014; Yeung et al., 2014). (B) Neurogenic and proliferative activities of SVZ NSCs in rodent, dog, human, and dolphin. Please note that neurogenic activity disappears in human at $\sim 18$ months, and is completely absent in dolphin postnatally; however, both species can suffer from GBM at adulthood. Kindly refer to the main text for further details.

the lineage-tracing experiment by using genetically engineered mouse models (GEMMs). Taking advantage of NSC-specific genetic tools such as hGFAP-Cre, Nestin-Cre, or Nestin-Cre ${ }^{\text {ER }}$, Parada and his colleagues showed that mouse NSCs are capable of transforming into high-grade gliomas after the loss of Trp53, NF1 and/or PTEN (Zhu et al., 2005; Chen et al., 2012; Alcantara Llaguno et al., 2015).
While these multiple lines of evidence demonstrate that NSCs are capable of transforming into malignancy, several important issues should be understood. Firstly, as already mentioned, recent findings about NSC biology challenges the concept that a single SVZ aNSC can repeatedly self-renew, therefore greatly decreasing the possibility for an aNSC to accumulate mutations, as previously assumed. Secondly, the stem cell feature of CSCs 
need not necessarily be inherited from tissue stem cells; it can also be regained through the de-differentiation of lineage-committed progenitors or mature cells (Batlle and Clevers, 2017). Thirdly, many claimed that NSC cellular markers are not specific to NSCs. For example, the most widely used NSC marker Nestin, an intermediate filament protein expressed in radial glia and adult $\mathrm{B} 1$ cells, is prominently expressed in reactive astrocytes (Ernst and Christie, 2006). Although partial overlaps between brain tumor locations and the NSC niche is a good argument to support the fact that gliomas originate from adult NSCs in patients, a recent work revealed that the SVZ may merely function as a niche toward which glioma cells prefer to migrate (Qin et al., 2017).

An additional dimension of complexity comes from the nature of NSCs per se. As NSCs can readily differentiate into fatecommitted precursors such as OPCs or mature astrocytes, it is unclear whether NSCs, after acquiring initial mutations, directly transform, or they must proceed through the status of lineagecommitted cell types prior to the final transformation. In fact, by using a single-cell resolution genetic mouse model termed mosaic analysis with double markers (MADM), we have shown that introducing $p 53$ and NF1 mutations into NSCs did not evidently change the proliferation rate of pre-cancerous adult NSCs, but drastically promoted the over-expansion of descendant OPCs, arguing against a direct transformation of NSCs, at least in the context of this mutation combination (Liu et al., 2011).

\section{OPCs as the Cell of Origin: Evidence and Some Updates}

Oligodendrocyte precursor cells have been proposed as an important cell of origin for glioma since they were first identified. As already mentioned, OPCs represent the largest proliferation pool in the brain, and exhibit remarkable selfrenewal capacity both in vitro and in vivo, and are therefore suitable, as cells of origin, to accumulate genetic mutations. In fact, NG2, one of the most commonly used OPC cell marker, was initially isolated from a rat glioma model (Stallcup, 1981). In addition to NG2, we and others showed that many cellular markers typically expressed in OPCs, such as Olig2, PDGFRa, and O4, were also expressed in most, if not all, human malignant gliomas (Shoshan et al., 1999; Ligon et al., 2004, 2007; Rebetz et al., 2008; Ledur et al., 2016; Shao et al., 2017). Furthermore, over-expression of the oncogenic form of EGFR (EGFRvIII) under the promoter S100b, a non-stem cell marker (Raponi et al., 2007), induced gliomas recapitulating the pathological features of human oligodendroglioma (Weiss et al., 2003; Persson et al., 2010). Moreover, overexpression of PDGF-BB alone, or when combined with p53 and Pten deactivation, was shown to be able to effectively transform rat and mouse OPCs into lower-grade oligodendrogliomas or high-grade gliomas (Assanah et al., 2006; Lindberg et al., 2009; Lei et al., 2011; Lu et al., 2016). More direct evidence to support the OPC-origin of high-grade gliomas comes from fatemapping experiments. By using OPC-specific NG2-Cre or NG2$\mathrm{Cre}^{\mathrm{ERT}}$ transgenic mouse lines, we and others have provided convincing evidence that OPCs, after acquiring Trp53 and
NF1 mutations, can be directly transformed into malignant gliomas resembling the proneural subtype of GBM, whenever the mutations were introduced in early or adult stage (Liu et al., 2011; Galvao et al., 2014; Alcantara Llaguno et al., 2015).

The data from our group show that OPC-like tumor cells are universally present in all human malignant gliomas, and share remarkable similarities in many aspects with their counterparts found in mouse genetic models, in which OPCs are the defined cells of origin (Ledur et al., 2016; Shao et al., 2017). These lines of evidence collectively lead to a reasonable assumption that OPCs are important glioma cells of origin in patients.

\section{Mature Astrocytes and Neurons as the Cells of Origin: An Unsettled Issue}

Whether mature astrocytes and/or neurons are able to directly transform remains highly debated. Chow et al. (2011) utilized GFAP-Cre ${ }^{\text {ER }}$ to introduce Trp53, Pten and/or Rb1 mutations into astrocytes and induced high-grade astrocytomas in adult mice. Also using GFAP-Cre ${ }^{\text {ER }}$, Vitucci et al. (2017) observed that murine astrocytes could transform into highgrade glioma mimicking human mesenchymal, proneural, and neural GBMs. By using Cre-activatable lentiviral vehicles that encoded shRNA against Trp53 and NF1, FriedmannMorvinski et al. (2012) reported high incidence of GBMs when they transfected such lentiviral particles into the brains of hGFAP-Cre, Synapsin I-Cre or CamK2a-Cre transgenic mice. Therefore, the authors claimed that both mature astrocytes and neurons can function as the cells of origin for GBMs through dedifferentiation. Nevertheless, as most claimed astrocytespecific markers such as GFAP are also expressed in NSCs (Chaker et al., 2016), and those for neurons like Synapsin-1 are also expressed in OPCs [(Cahoy et al., 2008; Zhang et al., 2014) and personal observations], further validation is necessary to exclude the possibility of targeting NSCs and/or OPCs when attempting to manipulate mature astrocytes or neurons. Highly specific genetic tools are warranted to clarify this fundamental issue.

\section{HUMAN RELEVANCE: NEW DATA AND THE INSIGHT FROM COMPARATIVE STUDIES}

Most of our current knowledge on glioma cell of origin was derived from the observations on animal models, mostly GEMMbased cancer models. One fundamental question we must confront is that how much of the landscape depicted thus far can be directly extrapolated to human cases. Despite the overall anatomical structures and developmental principles of the CNS being highly conserved among mammals, notable differences, particularly in the properties of adult NSCs, do exist among species. Recognizing these differences has important impacts on shaping our understandings of the glioma cell of origin in humans. 


\section{Adult NSCs May Not Be a Major Player in the Pathogenesis of Glioblastoma in Human or Other Large-Brained Animals}

Unlike in rodents, where NSCs and neural progenitors proliferate continuously to form new neurons, in large-brained mammals, such as humans, SVZ neurogenesis declines drastically during postnatal life (Lipp and Bonfanti, 2016; Paredes et al., 2016), and fully disappears at around 18 months (Sanai et al., 2011), long before high-grade gliomas are diagnosed. Consistent with this observation, by measuring the turnover rate of nuclear bomb test-derived ${ }^{14} \mathrm{C}$ in genomic DNA, Bergmann et al. (2012, 2015) showed that there is virtually no postnatal neurogenesis in the human $\mathrm{OB}$.

Direct evidence to support a lack of marked levels of neurogenesis or self-renewal of NSCs in the adult human SVZ comes from immunohistological studies, where proliferative cells were rarely found in the SVZ in adults (Wang et al., 2011; Dennis et al., 2016). Furthermore, the density of dividing cells in the SVZ is comparable to or even lower than that in other regions such as the corpus callosum (Shao et al. personal observations). Despite the suggestion that certain pathological conditions such as ischemic stroke may activate NSCs in the adult human brain (Jin et al., 2006; Marti-Fabregas et al., 2010), this conclusion was disproved by the ${ }^{14} \mathrm{C}$ turnover assay (Huttner et al., 2014). Regardless the potential of adult NSCs to be activated in vivo after injury, no definitive evidence yet shows an association of human glioma pathogenesis with any pathological lesions.

Comparative studies between species provide deeper insights into questioning the relevance of adult NSCs in glioma pathogenesis (as summarized in Figure 1B). Unlike humans, but quite similar to rodents, dogs possess SVZ neurogenesis that persists into adulthood (Malik et al., 2012). Therefore, one may expect a much higher incidence of gliomagenesis in dogs, if adult NSCs indeed play critical roles in initiating glioma. Contrary to this speculation, epidemiological studies suggest that the incidence of spontaneous brain tumors in dogs is remarkably similar to that in humans, i.e., approximately 20 in 100,000 per year (Dobson et al., 2002; Hicks et al., 2017). On the other hand, aquatic mammals such as dolphins, which lack a functional periventricular germinal layer postnatally and any detectable dividing cells within the SVZ (Parolisi et al., 2017), can surely suffer from glioblastoma (Diaz-Delgado et al., 2015). These findings, together with those in rodent NSCs, contradict the argument that adult NSCs play major roles in initiating gliomagenesis.

\section{Adult OPCs May Function as an Important Cell of Origin with Strong Human Relevance}

Unlike the great variations of cellular behaviors of adult NSCs, the renewal capacity of OPCs are largely conserved across species. For instance, immunohistological studies show that, although sparse, OPCs are the major cycling cells in the adult human brain (Geha et al., 2010). In line with this observation, ${ }^{14} \mathrm{C}$ data revealed that gray matter oligodendrocytes do not reach a plateau until the fourth decade of life, even after which the annual turnover remains as high as $2.5 \%$ (Yeung et al., 2014). These results in collection clearly demonstrate that OPCs undergo substantial renewal in the adult human brain.

Interestingly, the proliferation rate of OPCs are significantly elevated in epileptic patients (Geha et al., 2010). As epilepsies are frequently associated with glioma patients (Iuchi et al., 2015; Englot et al., 2016), these observations raise an intriguing possibility that aberrant neuronal activity may directly contribute to OPC self-renewals and, most likely, to oncogenic transformation. This hypothesis has been recently substantiated by showing that artificially enhancing the neuronal activity in GEMMs through optogenetic approaches can stimulate the proliferation of normal resident OPCs and engrafted human GBM cells (Gibson et al., 2014; Venkatesh et al., 2015).

Therefore, although comprehensive studies are warranted to systematically characterize the relative proliferating capacities of OPCs and NSCs/NPCs in the adult human brain in situ, given that OPCs retain a relatively decent level of self-renewal activity, and significantly outnumber NSCs in the adult human brain, they remain a highly probable candidate for the cell of origin of human GBMs.

\section{THE RELATIONSHIP BETWEEN CELL(s) OF ORIGIN AND CANCER STEM CELLS (CSCs)}

It should be noted that the "CSC" is a functional definition that can only be assessed by the capacity of a cancer cell to initiate new tumors. Some studies identified CSCs from the NSC-derived GBM mouse models and showed that these NSCderived CSCs resemble normal NSCs in certain ways such as the expression of Nestin (Zheng et al., 2008; Alcantara Llaguno et al., 2009; Chen et al., 2012). However, the cells functioning as CSCs may not have to be derived and/or resemble normal NSCs. By using S100b- promoter-driven EGFRViii transgene, Persson et al. (2010) clearly showed that oligodendroglioma can be initiated from non NSCs, and the CSCs in this model can be identified and isolated based on their expression of NG2 (CSPG4), an OPC marker. We showed that CSCs derived from OPC-originated HGGs expressed NG2 as well as other OPC markers (such as PDGFRa and Olig2) and that the OPC feature is essential for the maintenance of the stemness of these CSCs (Liu et al., 2011; Ledur et al., 2016). Interestingly, OPC-originated CSCs gained the capacity to form spheres and to express Nestin. This latter observation implicates that Nestin is a marker for the stemness but not the cell identity in this particular case. In the human cases, NG2 have been used to enrich CSCs from oligodendrogliomas (Persson et al., 2010) and at least some GBMs (Persson et al., 2010; Al-Mayhani et al., 2011). Our own study showed that human primary GBM cell lines maintained under culture conditions that favor the enrichment of OPC-like tumor cells have enhanced malignancy (Ledur et al., 2016). In addition to OPCs, Schmid et al. (2016) provided the evidence that 
TABLE 1 | Pathological features and molecular signatures of currently reported GEMMs for gliomas.

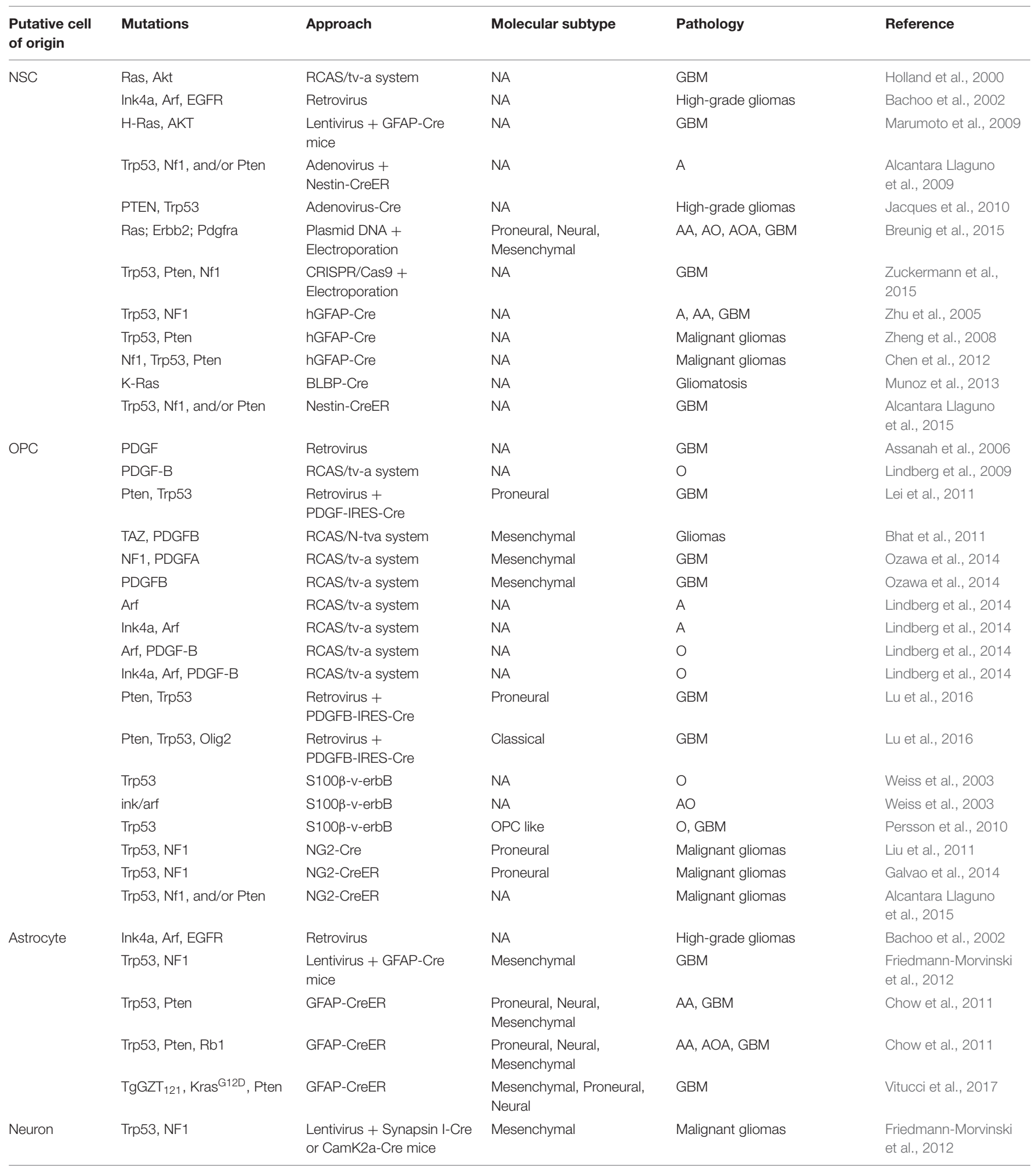

A, astrocytoma; $O$, oligodendroglioma; $A A$, anaplastic astrocytoma; $A O$, anaplastic oligodendroglioma; $A O A$, anaplastic oligoastrocytoma; GBM, glioblastoma multiforme.

mature astrocytes could dedifferentiate into glioma CSCs upon transformation. Therefore, CSCs in gliomas can definitely be developed from the non-CSC cell types. The detailed lineage relationship between NSCs, lineage-committed progenitors, mature cells and CSCs remains to be fully elucidated in the future studies. 


\section{THE RELATIONSHIP BETWEEN CELLS OF ORIGIN, TUMOR SUBTYPES AND HETEROGENEITY}

Cumulative evidence suggests that the same cell of origin can give rise to the GBMs manifesting different molecular features and that distinct types of cells of origin can evolve in parallel to give rise to tumors resembling similar molecular features (see also Table 1).

For instance, OPCs have been previously considered to mainly give rise to oligodendrogliomas and proneural subtype of GBMs (Weiss et al., 2003; Lei et al., 2011; Liu et al., 2011; Galvao et al., 2014). However, recent studies demonstrate that they can also serve as the cell of origin for astrocytoma (Lindberg et al., 2014) and other subtypes of GBMs, depending on the mutations initially introduced (Carro et al., 2009; Bhat et al., 2011, 2013; Lu et al., 2016). In particular, removal of Olig2 switches OPCderived proneural subtype of GBMs into the classical subtype. Over-expression of TAZ or suppression of NF1, instead, readily induces OPC-derived GBMs into the mesenchymal subtype (Bhat et al., 2011; Ozawa et al., 2014). Similar observations were also obtained in astrocyte-originated GBMs, where the same GEMM can give rise to tumors with highly heterogeneous profiles (Chow et al., 2011; Schmid et al., 2016).

Importantly, the evolution routes of a defined cell of origin may also affect the molecular features of brain tumors. The recurrent GBMs from the same patients frequently switched their molecular features when compared to their primary tumor counterparts (Kim H. et al., 2015; Kim J. et al., 2015; Wang et al., 2016). Therefore, the molecular signature of a particular transformed tumor may not always reliably predict its cell of origin.

\section{FUTURE PERSPECTIVES}

Owing to genetic lineage tracing techniques and other advanced biological methods, tremendous progress has been made in

\section{REFERENCES}

Alcantara Llaguno, S., Chen, J., Kwon, C.-H., Jackson, E. L., Li, Y., Burns, D. K., et al. (2009). Malignant astrocytomas originate from neural stem/progenitor cells in a somatic tumor suppressor mouse model. Cancer Cell 15, 45-56. doi: 10.1016/j.ccr.2008.12.006

Alcantara Llaguno, S. R., Wang, Z., Sun, D., Chen, J., Xu, J., Kim, E., et al. (2015). Adult lineage-restricted CNS progenitors specify distinct glioblastoma subtypes. Cancer Cell 28, 429-440. doi: 10.1016/j.ccell.2015.09.007

Al-Mayhani, M. T., Grenfell, R., Narita, M., Piccirillo, S., Kenney-Herbert, E., Fawcett, J. W., et al. (2011). NG2 expression in glioblastoma identifies an actively proliferating population with an aggressive molecular signature. Neuro Oncol. 13, 830-845. doi: 10.1093/neuonc/nor088

Alvarez-Buylla, A., Garcia-Verdugo, J. M., and Tramontin, A. D. (2001). A unified hypothesis on the lineage of neural stem cells. Nat. Rev. Neurosci. 2, 287-293. doi: $10.1038 / 35067582$

Assanah, M., Lochhead, R., Ogden, A., Bruce, J., Goldman, J., and Canoll, P. (2006). Glial progenitors in adult white matter are driven to form malignant gliomas by platelet-derived growth factor-expressing retroviruses. J. Neurosci. 26, 6781-6790. doi: 10.1523/Jneurosci.0514-06.2006 understanding the glioma cell of origin during the past decade. Now, a consensus has been made that several important cell types, particularly NSCs and OPCs, are capable of transforming at least in GEMMs. However, many fundamental questions remain unanswered. For instance, is there a universal cell type functioning as the cell of origin for all gliomas in humans? Or alternatively, do different cell types give rise to gliomas with distinct pathological identities? Can different mutations drive the same cell of origin to follow the same or distinct routes toward the final transformation? When exactly do human gliomas form? GEMMs will surely continue to serve as the most important tools to address these fundamental questions. Nevertheless, we should be aware of the difference between GEMMs and patients. Newer methods and the concept of comparative pathology could help us identify what really initiates this devastating form of cancer in humans.

\section{AUTHOR CONTRIBUTIONS}

FS and CL wrote the manuscript. FS prepared the figure and the table.

\section{FUNDING}

This work was supported by the National Key Research and Development Program of China, Stem Cell and Translational Research (2016YFA0101201 to CL), Science Foundation for Distinguished Young Scientists of Zhejiang Province (LR17H160001 to CL), National Natural Science Foundation of China (81673035 to CL), and Thousand Talent Program for Young Outstanding Scientists, China (to CL).

\section{ACKNOWLEDGMENTS}

We thank Drs. Weijun Yang and Yingjie Wang for their critical comments.

Bachoo, R. M., Maher, E. A., Ligon, K. L., Sharpless, N. E., Chan, S. S., You, M. J. J., et al. (2002). Epidermal growth factor receptor and Ink4a/Arf: convergent mechanisms governing terminal differentiation and transformation along the neural stem cell to astrocyte axis. Cancer Cell 1, 269-277. doi: 10.1016/S15356108(02)00046-6

Bao, S. D., Wu, Q. L., Mclendon, R. E., Hao, Y. L., Shi, Q., Hjelmeland, A. B., et al. (2006). Glioma stem cells promote radioresistance by preferential activation of the DNA damage response. Nature 444, 756-760. doi: 10.1038/nature 05236

Barami, K., Sloan, A. E., Rojiani, A., Schell, M. J., Staller, A., and Brem, S. (2009). Relationship of gliomas to the ventricular walls. J. Clin. Neurosci. 16, 195-201. doi: 10.1016/j.jocn.2008.03.006

Batlle, E., and Clevers, H. (2017). Cancer stem cells revisited. Nat. Med. 23, 1124-1134. doi: 10.1038/nm.4409

Bergmann, O., Liebl, J., Bernard, S., Alkass, K., Yeung, M. S., Maggie, S. Y., et al. (2012). The age of olfactory bulb neurons in humans. Neuron 74, 634-639. doi: 10.1016/j.neuron.2012.03.030

Bergmann, O., Spalding, K. L., and Frisen, J. (2015). Adult neurogenesis in humans. Cold Spring Harb. Perspect. Biol. 7:a018994. doi: 10.1101/cshperspect. a018994 
Bhat, K. P. L., Balasubramaniyan, V., Vaillant, B., Ezhilarasan, R., Hummelink, K., Hollingsworth, F., et al. (2013). Mesenchymal differentiation mediated by $\mathrm{NF}-\kappa \mathrm{B}$ promotes radiation resistance in glioblastoma. Cancer Cell 24, 331-346. doi: 10.1016/j.ccr.2013.08.001

Bhat, K. P. L., Salazar, K. L., Balasubramaniyan, V., Wani, K., Heathcock, L., Hollingsworth, F., et al. (2011). The transcriptional coactivator TAZ regulates mesenchymal differentiation in malignant glioma. Genes Dev. 25, 2594-2609. doi: 10.1101/gad.176800.111

Brennan, C. W., Verhaak, R. G. W., Mckenna, A., Campos, B., Noushmehr, H., Salama, S. R., et al. (2013). The somatic genomic landscape of glioblastoma. Cell 155, 462-477. doi: 10.1016/j.cell.2013.09.034

Breunig, J. J., Levy, R., Antonuk, C. D., Molina, J., Dutra-Clarke, M., Park, H., et al. (2015). Ets factors regulate neural stem cell depletion and gliogenesis in Ras pathway glioma. Cell Rep. 12, 258-271. doi: 10.1016/j.celrep.2015.06.012

Cahoy, J. D., Emery, B., Kaushal, A., Foo, L. C., Zamanian, J. L., Christopherson, K. S., et al. (2008). A transcriptome database for astrocytes, neurons, and oligodendrocytes: a new resource for understanding brain development and function. J. Neurosci. 28, 264-278. doi: 10.1523/Jneurosci.4178-07.2008

Carro, M. S., Lim, W. K., Alvarez, M. J., Bollo, R. J., Zhao, X., Snyder, E. Y., et al. (2009). The transcriptional network for mesenchymal transformation of brain tumours. Nature 463, 318-325. doi: 10.1038/nature08712

Chaffer, C. L., and Weinberg, R. A. (2015). How does multistep tumorigenesis really proceed? Cancer Discov. 5, 22-24. doi: 10.1158/2159-8290.cd-14-0788

Chaker, Z., Codega, P., and Doetsch, F. (2016). A mosaic world: puzzles revealed by adult neural stem cell heterogeneity. Wiley Interdiscip. Rev. Dev. Biol. 5 , 640-658. doi: 10.1002/wdev.248

Chen, J., Li, Y. J., Yu, T. S., Mckay, R. M., Burns, D. K., Kernie, S. G., et al. (2012). A restricted cell population propagates glioblastoma growth after chemotherapy. Nature 488, 522-526. doi: 10.1038/nature11287

Chow, L. M. L., Endersby, R., Zhu, X. Y., Rankin, S., Qu, C. X., Zhang, J. Y., et al. (2011). Cooperativity within and among Pten, p53, and Rb pathways induces high-grade astrocytoma in adult brain. Cancer Cell 19, 305-316. doi: 10.1016/j.ccr.2011.01.039

Codega, P., Silva-Vargas, V., Paul, A., Maldonado-Soto, A. R., Deleo, A. M., Pastrana, E., et al. (2014). Prospective identification and purification of quiescent adult neural stem cells from their in vivo niche. Neuron 82, 545-559. doi: 10.1016/j.neuron.2014.02.039

Dawson, M. R. L., Polito, A., Levine, J. M., and Reynolds, R. (2003). NG2expressing glial progenitor cells: an abundant and widespread population of cycling cells in the adult rat CNS. Mol. Cell. Neurosci. 24, 476-488. doi: 10.1016/ S1044-7431(03)00210-0

Dennis, C. V., Suh, L. S., Rodriguez, M. L., Kril, J. J., and Sutherland, G. T. (2016). Human adult neurogenesis across the ages: an immunohistochemical study. Neuropathol. Appl. Neurobiol. 42, 621-638. doi: 10.1111/nan.12337

Diaz-Delgado, J., Sacchino, S., Suarez-Bonnet, A., Sierra, E., Arbelo, M., Espinosa, A., et al. (2015). High-grade astrocytoma (glioblastoma multiforme) in an Atlantic spotted dolphin (Stenella frontalis). J. Comp. Pathol. 152, 278-282. doi: $10.1016 /$ j.jcpa.2014.12.016

Dobson, J. M., Samuel, S., Milstein, H., Rogers, K., and Wood, J. L. N. (2002). Canine neoplasia in the UK: estimates of incidence rates from a population of insured dogs. J. Small Anim. Pract. 43, 240-246. doi: 10.1111/j.1748-5827.2002. tb00066.x

Doetsch, F., Caille, I., Lim, D. A., Garcia-Verdugo, J. M., and Alvarez-Buylla, A. (1999). Subventricular zone astrocytes are neural stem cells in the adult mammalian brain. Cell 97, 703-716. doi: 10.1016/S0092-8674(00)80783-7

Duan, S. L., Yuan, G. H., Liu, X. M., Ren, R. T., Li, J. Y., Zhang, W. Z., et al. (2015). PTEN deficiency reprogrammes human neural stem cells towards a glioblastoma stem cell-like phenotype. Nat. Commun. 6:10068. doi: 10.1038/ ncomms 10068

Englot, D. J., Chang, E. F., and Vecht, C. J. (2016). Epilepsy and brain tumors. Handb. Clin. Neurol. 134, 267-285. doi: 10.1016/b978-0-12-802997-8.00016-5

Ernst, C., and Christie, B. R. (2006). The putative neural stem cell marker, nestin, is expressed in heterogeneous cell types in the adult rat neocortex. Neuroscience 138, 183-188. doi: 10.1016/j.neuroscience.2005.10.065

Friedmann-Morvinski, D., Bushong, E. A., Ke, E., Soda, Y., Marumoto, T., Singer, O., et al. (2012). Dedifferentiation of neurons and astrocytes by oncogenes can induce gliomas in mice. Science 338, 1080-1084. doi: 10.1126/ science. 1226929
Fuentealba, L. C., Rompani, S. B., Parraguez, J. I., Obernier, K., Romero, R., Cepko, C. L., et al. (2015). Embryonic origin of postnatal neural stem cells. Cell 161, 1644-1655. doi: 10.1016/j.cell.2015.05.041

Furutachi, S., Miya, H., Watanabe, T., Kawai, H., Yamasaki, N., Harada, Y., et al. (2015). Slowly dividing neural progenitors are an embryonic origin of adult neural stem cells. Nat. Neurosci. 18, 657-665. doi: 10.1038/nn.3989

Galvao, R. P., Kasina, A., Mcneill, R. S., Harbin, J. E., Foreman, O., Verhaak, R. G. W., et al. (2014). Transformation of quiescent adult oligodendrocyte precursor cells into malignant glioma through a multistep reactivation process. Proc. Natl. Acad. Sci. U.S.A. 111, E4214-E4223. doi: 10.1073/pnas.1414389111

Garcia-Marques, J., Nunez-Llaves, R., and Lopez-Mascaraque, L. (2014). NG2-glia from pallial progenitors produce the largest clonal clusters of the brain: time frame of clonal generation in cortex and olfactory bulb. J. Neurosci. 34, 23052313. doi: 10.1523/Jneurosci.3060-13.2014

Geha, S., Pallud, J., Junier, M.-P., Devaux, B., Leonard, N., Chassoux, F., et al. (2010). NG2 ${ }^{+} /$Olig2 ${ }^{+}$cells are the major cycle-related cell population of the adult human normal brain. Brain Pathol. 20, 399-411. doi: 10.1111/j.1750-3639. 2009.00295. $\mathrm{x}$

Gibson, E. M., Purger, D., Mount, C. W., Goldstein, A. K., Lin, G. L., Wood, L. S., et al. (2014). Neuronal activity promotes oligodendrogenesis and adaptive myelination in the mammalian brain. Science 344:1252304. doi: 10.1126/ science. 1252304

Hicks, J., Platt, S., Kent, M., and Haley, A. (2017). Canine brain tumours: a model for the human disease? Vet. Comp. Oncol. 15, 252-272. doi: 10.1111/vco.12152

Holland, E. C., Celestino, J., Dai, C., Schaefer, L., Sawaya, R. E., and Fuller, G. N. (2000). Combined activation of Ras and Akt in neural progenitors induces glioblastoma formation in mice. Nat. Genet. 25, 55-57. doi: 10.1038/75596

Huttner, H. B., Bergmann, O., Salehpour, M., Racz, A., Tatarishvili, J., Lindgren, E., et al. (2014). The age and genomic integrity of neurons after cortical stroke in humans. Nat. Neurosci. 17, 801-803. doi: 10.1038/nn.3706

Iuchi, T., Hasegawa, Y., Kawasaki, K., and Sakaida, T. (2015). Epilepsy in patients with gliomas: incidence and control of seizures. J. Clin. Neurosci. 22, 87-91. doi: 10.1016/j.jocn.2014.05.036

Jacques, T. S., Swales, A., Brzozowski, M. J., Henriquez, N. V., Linehan, J. M., Mirzadeh, Z., et al. (2010). Combinations of genetic mutations in the adult neural stem cell compartment determine brain tumour phenotypes. EMBO J. 29, 222-235. doi: 10.1038/emboj.2009.327

Jin, K. L., Wang, X. M., Xie, L., Mao, X. O., Zhu, W., Wang, Y., et al. (2006). Evidence for stroke-induced neurogenesis in the human brain. Proc. Natl. Acad. Sci. U.S.A. 103, 13198-13202. doi: 10.1073/pnas.0603512103

Kim, H., Zheng, S., Amini, S. S., Virk, S. M., Mikkelsen, T., Brat, D. J., et al. (2015). Whole-genome and multisector exome sequencing of primary and posttreatment glioblastoma reveals patterns of tumor evolution. Genome Res. 25, 316-327. doi: 10.1101/gr.180612.114

Kim, J., Lee, I. H., Cho, H. J., Park, C. K., Jung, Y. S., Kim, Y., et al. (2015). Spatiotemporal evolution of the primary glioblastoma genome. Cancer Cell 28, 318-328. doi: 10.1016/j.ccell.2015.07.013

Kondo, T., and Raff, M. (2000). Oligodendrocyte precursor cells reprogrammed to become multipotential CNS stem cells. Science 289, 1754-1757. doi: 10.1126/ science.289.5485.1754

Ledur, P. F., Liu, C., He, H., Harris, A. R., Minussi, D. C., Zhou, H. Y., et al. (2016). Culture conditions tailored to the cell of origin are critical for maintaining native properties and tumorigenicity of glioma cells. Neuro Oncol. 18, 1413-1424. doi: 10.1093/neuonc/now062

Lei, L., Sonabend, A. M., Guarnieri, P., Soderquist, C., Ludwig, T., Rosenfeld, S., et al. (2011). Glioblastoma models reveal the connection between adult glial progenitors and the proneural phenotype. PLoS One 6:e20041. doi: 10.1371/ journal.pone.0020041

Ligon, K. L., Alberta, J. A., Kho, A. T., Weiss, J., Kwaan, M. R., Nutt, C. L., et al. (2004). The oligodendroglial lineage marker OLIG2 is universally expressed in diffuse gliomas. J. Neuropathol. Exp. Neurol. 63, 499-509. doi: 10.1093/jnen/63. 5.499

Ligon, K. L., Huillard, E., Mehta, S., Kesari, S., Liu, H. Y., Alberta, J. A., et al. (2007) Olig2-regulated lineage-restricted pathway controls replication competence in neural stem cells and malignant glioma. Neuron 53, 503-517. doi: 10.1016/j. neuron.2007.01.009

Lindberg, N., Jiang, Y., Xie, Y., Bolouri, H., Kastemar, M., Olofsson, T., et al. (2014). Oncogenic signaling is dominant to cell of origin and dictates astrocytic 
or oligodendroglial tumor development from oligodendrocyte precursor cells. J. Neurosci. 34, 14644-14651. doi: 10.1523/jneurosci.2977-14.2014

Lindberg, N., Kastemar, M., Olofsson, T., Smits, A., and Uhrbom, L. (2009). Oligodendrocyte progenitor cells can act as cell of origin for experimental glioma. Oncogene 28, 2266-2275. doi: 10.1038/onc.2009.76

Lipp, H. P., and Bonfanti, L. (2016). Adult neurogenesis in mammals: variations and confusions. Brain Behav. Evol. 87, 205-221. doi: 10.1159/00044 6905

Liu, C., Sage, J. C., Miller, M. R., Verhaak, R. G. W., Hippenmeyer, S., Vogel, H., et al. (2011). Mosaic analysis with double markers reveals tumor cell of origin in glioma. Cell 146, 209-221. doi: 10.1016/j.cell.2011.06.014

Louis, D. N. (2006). Molecular pathology of malignant gliomas. Annu. Rev. Pathol. Mech. Dis. 1, 97-117. doi: 10.1146/annurev.pathol.1.110304. 100043

Lu, F. H., Chen, Y., Zhao, C. T., Wang, H. B., He, D. Y., Xu, L. L., et al. (2016). Olig2-dependent reciprocal shift in PDGF and EGF receptor signaling regulates tumor phenotype and mitotic growth in malignant glioma. Cancer Cell 29, 669-683. doi: 10.1016/j.ccell.2016.03.027

Malik, S. Z., Lewis, M., Isaacs, A., Haskins, M., Van Winkle, T., Vite, C. H., et al. (2012). Identification of the rostral migratory stream in the canine and feline brain. PLoS One 7:e36016. doi: 10.1371/journal.pone.0036016

Marti-Fabregas, J., Romaguera-Ros, M., Gomez-Pinedo, U., Martinez-Ramirez, S., Jimenez-Xarrie, E., Marín, R., et al. (2010). Proliferation in the human ipsilateral subventricular zone after ischemic stroke. Ann. Neurosci. 17, 134-135. doi: 10.5214/ans.0972-7531.1017308

Marumoto, T., Tashiro, A., Friedmann-Morvinski, D., Scadeng, M., Soda, Y., Gage, F. H., et al. (2009). Development of a novel mouse glioma model using lentiviral vectors. Nat. Med. 15, 110-116. doi: 10.1038/nm.1863

Ming, G. L., and Song, H. J. (2011). Adult neurogenesis in the mammalian brain: significant answers and significant questions. Neuron 70, 687-702. doi: 10.1016/ j.neuron.2011.05.001

Munoz, D. M., Singh, S., Tung, T., Agnihotri, S., Nagy, A., Guha, A., et al. (2013). Differential transformation capacity of neuro-glial progenitors during development. Proc. Natl. Acad. Sci. U.S.A. 110, 14378-14383. doi: 10.1073/pnas. 1303504110

Nishiyama, A., Komitova, M., Suzuki, R., and Zhu, X. Q. (2009). Polydendrocytes (NG2 cells): multifunctional cells with lineage plasticity. Nat. Rev. Neurosci. 10, 9-22. doi: $10.1038 / \mathrm{nrn} 2495$

Ozawa, T., Riester, M., Cheng, Y. K., Huse, J. T., Squatrito, M., Helmy, K., et al. (2014). Most human non-GCIMP glioblastoma subtypes evolve from a common proneural-like precursor glioma. Cancer Cell 26, 288-300. doi: 10.1016/j.ccr.2014.06.005

Paredes, M. F., Sorrells, S. F., Garcia-Verdugo, J. M., and Alvarez-Buylla, A. (2016). Brain size and limits to adult neurogenesis. J. Comp. Neurol. 524, 646-664. doi: $10.1002 / \mathrm{cne} .23896$

Parolisi, R., Cozzi, B., and Bonfanti, L. (2017). Non-neurogenic SVZ-like niche in dolphins, mammals devoid of olfaction. Brain Struct. Funct. 222, 2625-2639. doi: 10.1007/s00429-016-1361-3

Perry, A., and Wesseling, P. (2016). Histologic classification of gliomas. Handb. Clin. Neurol. 134, 71-95. doi: 10.1016/b978-0-12-802997-8.00005-0

Persson, A. I., Petritsch, C., Swartling, F. J., Itsara, M., Sim, F. J., Auvergne, R., et al. (2010). Non-stem cell origin for oligodendroglioma. Cancer Cell 18, 669-682. doi: 10.1016/j.ccr.2010.10.033

Qin, E. Y., Cooper, D. D., Abbott, K. L., Lennon, J., Nagaraja, S., Mackay, A., et al. (2017). Neural precursor-derived pleiotrophin mediates subventricular zone invasion by glioma. Cell 170, 845.e19-859.e19. doi: 10.1016/j.cell.2017.07.016

Raponi, E., Agenes, F., Delphin, C., Assard, N., Baudier, J., Legraverend, C., et al. (2007). S100B expression defines a state in which GFAP-expressing cells lose their neural stem cell potential and acquire a more mature developmental stage. Glia 55, 165-177. doi: 10.1002/glia.20445

Rebetz, J., Tian, D., Persson, A., Widegren, B., Salford, L. G., Englund, E., et al. (2008). Glial progenitor-like phenotype in low-grade glioma and enhanced CD133-expression and neuronal lineage differentiation potential in high-grade glioma. PLoS One 3:e1936. doi: 10.1371/journal.pone. 0001936

Richardson, W. D., Young, K. M., Tripathi, R. B., and Mckenzie, I. (2011). NG2-glia as multipotent neural stem cells: fact or fantasy? Neuron 70, 661-673. doi: 10.1016/j.neuron.2011.05.013
Rivers, L. E., Young, K. M., Rizzi, M., Jamen, F., Psachoulia, K., Wade, A., et al. (2008). PDGFRA/NG2 glia generate myelinating oligodendrocytes and piriform projection neurons in adult mice. Nat. Neurosci. 11, 1392-1401. doi: $10.1038 / \mathrm{nn} .2220$

Sanai, N., Nguyen, T., Ihrie, R. A., Mirzadeh, Z., Tsai, H. H., Wong, M., et al. (2011). Corridors of migrating neurons in the human brain and their decline during infancy. Nature 478, 382-386. doi: 10.1038/nature10487

Schmid, R. S., Simon, J. M., Vitucci, M., Mcneill, R. S., Bash, R. E., Werneke, A. M., et al. (2016). Core pathway mutations induce de-differentiation of murine astrocytes into glioblastoma stem cells that are sensitive to radiation but resistant to temozolomide. Neuro Oncol. 18, 962-973. doi: 10.1093/neuonc/ nov321

Shao, F. J., Jiang, W. H., Gao, Q. Q., Li, B. Z., Sun, C. R., Wang, Q. Y., et al. (2017). Frozen tissue preparation for high-resolution multiplex histological analyses of human brain specimens. J. Neurooncol. 135, 21-28. doi: 10.1007/s11060-0172547-0

Shoshan, Y., Nishiyama, A., Chang, A. S., Mork, S., Barnett, G. H., Cowell, J. K., et al. (1999). Expression of oligodendrocyte progenitor cell antigens by gliomas: implications for the histogenesis of brain tumors. Proc. Natl. Acad. Sci. U.S.A. 96, 10361-10366. doi: 10.1073/pnas.96.18.10361

Singh, S. K., Hawkins, C., Clarke, I. D., Squire, J. A., Bayani, J., Hide, T., et al. (2004). Identification of human brain tumour initiating cells. Nature 432, 396-401. doi: $10.1038 /$ nature 03128

Snuderl, M., Fazlollahi, L., Le, L. P., Nitta, M., Zhelyazkova, B. H., Davidson, C. J., et al. (2011). Mosaic amplification of multiple receptor tyrosine kinase genes in glioblastoma. Cancer Cell 20, 810-817. doi: 10.1016/j.ccr.2011. 11.005

Stallcup, W. B. (1981). The Ng2 antigen, a putative lineage marker immunofluorescent localization in primary cultures of rat-brain. Dev. Biol. 83, 154-165. doi: 10.1016/S0012-1606(81)80018-8

Stiles, C. D., and Rowitch, D. H. (2008). Glioma stem cells: a midterm exam. Neuron 58, 832-846. doi: 10.1016/j.neuron.2008.05.031

Venkatesh, H. S., Johung, T. B., Caretti, V., Noll, A., Tang, Y. J., Nagaraja, S., et al. (2015). Neuronal activity promotes glioma growth through neuroligin-3 secretion. Cell 161, 803-816. doi: 10.1016/j.cell.2015. 04.012

Verhaak, R. G. W., Hoadley, K. A., Purdom, E., Wang, V., Qi, Y., Wilkerson, M. D., et al. (2010). Integrated genomic analysis identifies clinically relevant subtypes of glioblastoma characterized by abnormalities in PDGFRA, IDH1, EGFR, and NF1. Cancer Cell 17, 98-110. doi: 10.1016/j.ccr.2009.12.020

Vigano, F., and Dimou, L. (2016). The heterogeneous nature of NG2-glia. Brain Res. 1638, 129-137. doi: 10.1016/j.brainres.2015.09.012

Visvader, J. E. (2011). Cells of origin in cancer. Nature 469, 314-322. doi: 10.1038/ nature 09781

Vitucci, M., Irvin, D. M., Mcneill, R. S., Schmid, R. S., Simon, J. M., Dhruv, H. D., et al. (2017). Genomic profiles of low-grade murine gliomas evolve during progression to glioblastoma. Neuro Oncol. 19, 1237-1247. doi: 10.1093/neuonc/ nox050

Wang, C. M., Liu, F., Liu, Y. Y., Zhao, C. H., You, Y., Wang, L., et al. (2011). Identification and characterization of neuroblasts in the subventricular zone and rostral migratory stream of the adult human brain. Cell Res. 21, 1534-1550. doi: $10.1038 / \mathrm{cr} .2011 .83$

Wang, J. G., Cazzato, E., Ladewig, E., Frattini, V., Rosenbloom, D. I. S., Zairis, S., et al. (2016). Clonal evolution of glioblastoma under therapy. Nat. Genet. 48, 768-776. doi: 10.1038/ng.3590

Wang, Q. H., Hu, B. L., Hu, X., Kim, H., Squatrito, M., Scarpace, L., et al. (2017). Tumor evolution of glioma-intrinsic gene expression subtypes associates with immunological changes in the microenvironment. Cancer Cell 32, 42.e6-56.e6. doi: $10.1016 /$ j.ccell.2017.06.003

Weiss, W. A., Burns, M. J., Hackett, C., Aldape, K., Hill, J. R., Kuriyama, H., et al. (2003). Genetic determinants of malignancy in a mouse model for oligodendroglioma. Cancer Res. 63, 1589-1595.

Yeung, M. S. Y., Zdunek, S., Bergmann, O., Bernard, S., Salehpour, M., Alkass, K., et al. (2014). Dynamics of oligodendrocyte generation and myelination in the human brain. Cell 159, 766-774. doi: 10.1016/j.cell.2014. 10.011

Zhang, Y., Chen, K., Sloan, S. A., Bennett, M. L., Scholze, A. R., O'keeffe, S., et al. (2014). An RNA-sequencing transcriptome and splicing database of glia, 
neurons, and vascular cells of the cerebral cortex. J. Neurosci. 34, 11929-11947. doi: 10.1523/jneurosci.1860-14.2014

Zheng, H. W., Ying, H. Q., Yan, H. Y., Kimmelman, A. C., Hiller, D. J., and Chen, A. J. (2008). p53 and Pten control neural and glioma stem/progenitor cell renewal and differentiation. Nature 455, 1129-1133. doi: 10.1038/nature07443

Zhu, X. Q., Bergles, D. E., and Nishiyama, A. (2008). NG2 cells generate both oligodendrocytes and gray matter astrocytes. Development 135, 145-157. doi: $10.1242 / \mathrm{dev} .004895$

Zhu, X. Q., Hill, R. A., Dietrich, D., Komitova, M., Suzuki, R., and Nishiyama, A. (2011). Age-dependent fate and lineage restriction of single NG2 cells. Development 138, 745-753. doi: 10.1242/dev.047951

Zhu, Y., Guignard, F., Zhao, D. W., Liu, L., Burns, D. K., Mason, R. P., et al. (2005). Early inactivation of p53 tumor suppressor gene cooperating with NF1 loss induces malignant astrocytoma. Cancer Cell 8, 119-130. doi: 10.1016/j.ccr.2005. 07.004
Zuckermann, M., Hovestadt, V., Knobbe-Thomsen, C. B., Zapatka, M., Northcott, P. A., Schramm, K., et al. (2015). Somatic CRISPR/Cas9-mediated tumour suppressor disruption enables versatile brain tumour modelling. Nat. Commun. 6:7391. doi: $10.1038 /$ ncomms8391

Conflict of Interest Statement: The authors declare that the research was conducted in the absence of any commercial or financial relationships that could be construed as a potential conflict of interest.

Copyright $(2018$ Shao and Liu. This is an open-access article distributed under the terms of the Creative Commons Attribution License (CC BY). The use, distribution or reproduction in other forums is permitted, provided the original author(s) and the copyright owner are credited and that the original publication in this journal is cited, in accordance with accepted academic practice. No use, distribution or reproduction is permitted which does not comply with these terms. 